\title{
MEDICAL PROBLEMS OF A HIGH ALTITUDE HIMALAYAN EXPEDITION
}

\author{
CAPT T P FINNEGAN, MB, BS, BSc, RAMC \\ Expedition Medical Officer
}

\section{Introduction}

Exercise Himalayan Venture VI was the Army Mountaineering Association Expedition to Mount Api $(23,390 \mathrm{ft})$, West Nepal in the Spring of 1980. The expedition consisted of a party of 12 British servicemen accompanied by seven Nepalis travelling from Kathmandu by road through Nepal and India for one week to a roadhead at Dandeldhura, and then on foot through Far West Nepal for two weeks to a Base Camp at 13,500 ft (Fig 1).

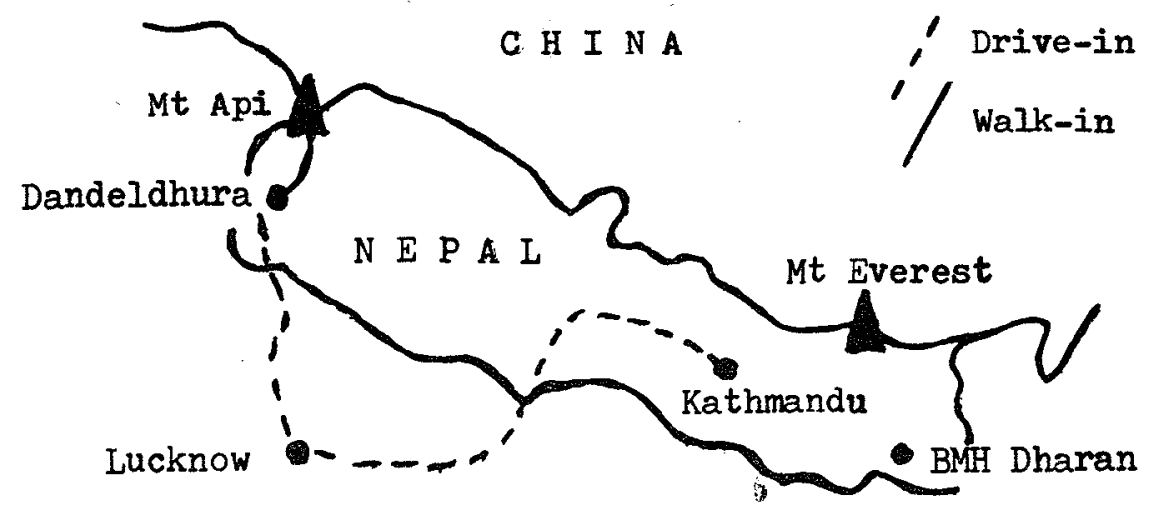

I N D I A

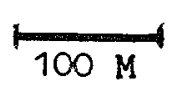

Fig 1. Sketch map of Army Mountaineering Association Expedition to Mount Api 1980

During the walk-in approximately 120 local Nepali porters accompanied the expedition. Seven weeks were spent climbing the mountain up to altitudes of $22,800 \mathrm{ft}$. After which the expedition returned to Kathmandu by a route similar to that described above. The author was fortunate enough to accompany the expedition as medical officer.

\section{Aim}

The aim of the paper is to describe in detail the medical problems of the expedition, and how they were dealt with.

All manner of expedition reports and books ${ }^{1-\tau}$ were read in an attempt to 
discover the best selection of equipment to take. Although these were helpful, undoubtedly the most useful advice was from doctors who had been on previous mountaineering expeditions ${ }^{8}{ }^{9}$. There is a great tendency to try to cover all eventualities, and to take too much of everything. This is especially relevant on a mountaineering expedition where all items have to be carried, resulting in the employment of additional porters, with a consequent drain on limited expedition funds. The most important factors to be taken into consideration were:-

a. To evaluate the needs of the 19 expedition members over a period of approximately four months and on a round trip Kathmandu/Base Camp of about 1,200 miles, together with the needs of about 120 locally employed porters.

b. To ascertain the facilities for evacuation, which were found to be about 10 days to organise helicopter evacuation from Base Camp, and how competent would the medical officer be on his own.

The expedition medical equipment consisted of over 100 items, less a few items which did not arrive, and is too lengthy to produce here. One item "DDT" was omitted from the list and was locally purchased in Kathmandu. It was considered probably not worth taking oxygen on medical grounds, as it is unlikely to be where it is needed and few expeditions take oxygen because of high altitude.

An instruction list was made for the medicines so that, in the absence of the medical officer, the expedition members would be able to use them if necessary. Some items which were considered to be likely to do more harm than good in lay hands were marked 'Doctors Use Only'. Table $I$ is a list of items issued to individual expedition members in Kathmandu for their own use.

Table I

Items issued to expedition members

\begin{tabular}{|c|c|c|c|}
\hline Item & & Item & Item \\
\hline Morphine syrette & 1 & Puritabs & First aid kit supplementary \\
\hline Mycotä powder & Tin & Anusol suppository & 6545-99-211-6258 (NATO \\
\hline Safety pins & 2 & Triangular bandage & Code No) Containing:- \\
\hline Elastoplasts & 7 & Amethocaine eye drops & Lomotil, salt and sugar \\
\hline Lipsalve & 1 & (single dose) & tablets, codeine phosphate, \\
\hline Insect repellent & Tube & Antiseptic & fortral, housewife, (less \\
\hline Uvistat & Tube & Algipan & paludrine and puritabs). \\
\hline
\end{tabular}

The collection and despatch of the medical equipment was organised through the Defence Medical Equipment Depot (DMED) whose help and advice were invaluable. Two visits were made to DMED to check on the weight and volume of the equipment and several important changes were made as a result. Fortunately, we were able to despatch the medical equipment through military channels, but it was originally planned that it would travel as normal 
civilian cargo and go through civilian customs. As a precaution against problems with customs an export certificate was obtained from the Department of Health and Social Security, Medicines Division. The equipment was packed in robust cardboard boxes which withstood the journey from the United Kingdom (UK) to Base Camp extremely well. At Base Camp the boxes were kept under canvas. A few medicines were taken above Base Camp for symptomatic use and these were:-

a. Anusol suppositories. b. Paracetamol tablets. c. Bradasol lozenges. d. Dequadine lozenges. e. Benzocaine lozenges. f. Ampicillin capsules and g. Maxolon tablets.

\section{Expedition members}

The selection of the expedition members had already been made by the leader when the author joined the team. Subsequently, two members experienced orthopaedic problems which resulted in their having to withdraw from the expedition. It was an advantage for the expedition to have a medical officer as he was able to discuss the medical problems with the doctors attending the members and then advise the leader.

The medical screening and preparation of the team was carried out by post as it was not practical to see them in person. Physical examination was not considered important by those from whom advice was sought, and with hindsight their view was borne out. A questionnaire sent to the members elicited the following interesting ailments:-

(a) A recent severe gun shot wound. (b) A severe allergy to aspirin. (c) A past history of frostbite. (d) A past history of five days unconsciousness following head injury. (e) Haemorrhoids (four people). (f) Various minor orthopaedic problems.

A covering letter to the questionnaire explained the need for medical and dental fitness and encouraged members to revise their knowledge of first aid. A letter to the doctors of the team requested that their blood group, haemoglobin, urinalysis and chest X-rays be checked. No unusual results were discovered and it is debatable how useful this sort of screening is in fit young men. Additionally, doctors were requested to ensure that expedition members were given an injection of immunoglobin and satisfactorily immunized against smallpox and cholera which were statutory requirements for Nepal at the time of the expedition, poliomyelitis, diphtheria, tetanus, typhoid, paratyphoid A and B, and tuberculosis. Malaria prophylaxis using weekly Daraprim (pyrimethamine) was initiated by the author in UK prior to departure.

Preventive dental treatment was considered very important as dental problems are a frequent cause of trouble on expeditions. The dentists of the members were individually asked to carry out a thorough dental check and any necessary treatment. Additionally, the author undertook a course of emergency dentistry, however it was not felt that complete competence had been achieved.

Research

The Ministry of Defence requests that all expeditions contact the Army 
Personnel Research Establishment to discover if there is any task which can easily and usefully be carried out. This was done, but there was no such task. However, a research project was successfuly undertaken involving the ambulatory monitoring of the electro-encephalogram, noting in particular the changes in sleep patterns during acclimatization. Detailed description of it is beyond the scope of this paper.

\section{Water and food}

The main concern of the author throughout the four months of the expedition was to try to ensure that the members did not develop unnecesary infections from food and water. In Kathmandu standards of hygiene varied from poor to non-existent, and drinking water was either boiled or treated with Puritabs. Food was bought in establishments which had a good reputation for cleanliness, and the tempting wares of the numerous street sellers were generally avoided. During the drive through India and Nepal and the walk-in water was boiled before consumption and it was possible to chlorinate the water in the tanks of the trucks that were used. Tea (chi) was bought at the infrequent chi shops during the walk-in and was considered safe as it was well boiled during preparation.

Base Camp (13,500 ft) was sited by a melt stream from the mountain snow and ice and was considered a safe source, which was borne out in practice. Above Base Camp all fluid for drinking and the reconstiution of dehydrated high altitude rations had to be melted from ice or snow, and this was a timeconsuming and tedious task. The result was that several of the members suffered from mild dehydration, and constant reminders were necessary to ensure that dehydration did not affect their working capacity. The problem of dehydration was exacerbated by three other factors, namely the dry air at altitude which increases respiratory fluid loss, the hard physical work of climbing which causes a significant fluid loss by sweat, and the intense sunshine during the day which encourages sweating.

Food was less of a problem as it was always well cooked and eaten hot. During the drive and walk-in local food brought from Kathmandu was eaten, and some of it was used at Base Camp to supplement 'compo rations'. Above Base Camp specially prepared dehydrated high altitude rations were eaten which provided 5000 calories per day. Despite this high intake all the expedition members lost some weight.

Constant awareness of hygiene resulted in few problems, and the most serious were several cases of giardiasis contracted on the return route from Base Camp to Kathmandu, and two cases of chronic diarrhoea on the mountain for no obvious cause.

Refuse

Rubbish was usually burnt at Base Camp, and an incinerator was built of stones for this purpose. The ash was buried. 'Cat sanitation' was used while travelling but at Base Camp a fixed site was designated as a lavatory about 100 yards 
down stream from the camp. The melt stream effectively prevented any build-up of faeces, and flies were not a problem because the camp was above snow line. The disposal of faeces into the melt stream was not considered to be a hazard to the health of the local population as the nearest habitation on the river was six days and some 6,500 ft downstream.

\section{Fitness}

Physical fitness was not a problem, as might be predicted in a group of well motivated young adult men. Interestingly, very few blisters were experienced during the walk-in, and only one continued to cause problems on the mountain. It was a tendo achilles ulcer, which eventually responded to mercurichrome orange soaks, and paraffin neotulle dressings. Psychological fitness was one of the problems predicted by the expedition leader who had considerable Himalayan experience. Although the members had much mountaineering experience many were lacking in expedition experience and only three had been to the Himalayas before. The size of the Himalayas, 1,600 miles long with a peak of 29,002 ft, is unique and it can inspire an awe in some people which adversely affects their desire to climb. A second potential problem is that on a small expedition there is a great need for everyone to work as a team and learn to overcome the petty irritations which living close together creates. The expedition leader and the author often discussed this problem, and noted how members were reacting to the mountain and each other.

Altitude sickness was discussed during the walk-in and the two cardinal rules of prevention were instilled namely, ascend slowly and if problems do occur, descend. Altitude fitness was achieved by gradual acclimatization. The walk-in provided good slow acclimatization to $13,500 \mathrm{ft}$. and 10 days were spent climbing around Base Camp up to $16,000 \mathrm{ft}$. Above Camp $1(16,700 \mathrm{ft})$ progress was slow enough to allow fair acclimatization and none of the major altitude ailments were encountered. Until they had acclimatized, all members of the expedition experienced symptoms of oxygen lack, that is insomnia, loss of appetite, headache, wooziness on standing, and breathlessness on exertion, but only one person experienced severe symptoms which necessitated his descent. He had severe headache, nausea and vomiting and was irritable with his fellows.

\section{Hearts and minds}

It was considered not only impractical, but also wrong for a peripatetic expedition to attempt any serious 'hearts and minds' campaign for the population encountered during the walk-in and walk-out. However, inevitably wherever camp was made a queue of local people would form and the author held a 'clinic'. The majority of the problems were chronic and incurable given the resources of Nepal, but obvious cases of tuberculosis were directed to the local hospital which was usually four to seven days walk away, and sufficient quantities of aspirin, vitamins and skin antiseptics had been taken to allow some simple palliative treatment. During the walk-out from the mountain surplus medical supplies were given to the one mission station with an American doctor and the one bare-foot (literally) doctor encountered. 
Medical problems

Table II lists the medical ailments suffered by members. There were only four problems with potentially serious consequences, which was fortunate as it would have taken about 10 days to organise a helicopter evacuation from Base Camp, these were:-

Table II

Ailments suffered by expedition members

\begin{tabular}{lll}
\hline \multicolumn{1}{c}{ Ailment } & \multicolumn{1}{c}{ Ailment } & \multicolumn{1}{c}{ Ailment } \\
\hline Acute mountain sickness & Vomiting and diarrhoea & Indigestion \\
Aphthous ulcers & Frostbite & Insect bites \\
Blisters & Frostnip & Insomnia \\
Bronchitis & Giardiasis & Lost tooth filling \\
Concussion & Gingivitis & Skeleto-muscular strains \\
Constipation & Haemorrhoids & Sunburn \\
Coughs and sore throats & Hay fever & Tonsillitis \\
Diarrhoea-chronic and & Headaches & Toothache \\
\multicolumn{1}{c}{ acute } & Hyphaema with unilateral & \\
& \multicolumn{2}{c}{ blindness } \\
\hline
\end{tabular}

i. A case of unilateral blindness with hyphaema, caused by being hit by a falling rock at $18,400 \mathrm{ft}$. Treatment consisted of evacuation to Base Camp and rest. Day vision recovered in a week, but night vision took three weeks to recover. This was a significant handicap as much of the climbing had to be done at night because of snow conditions.

ii. A case of concussion following a head injury from falling ice at 18,400 $\mathrm{ft}$. Treatment was rest for one day at the camp below at $16,700 \mathrm{ft}$.

iii. A case of acute mountain sickness at $16,400 \mathrm{ft}$. which was cured by descent to Base Camp at 13,500 ft.

iv. A case of bilateral frostbite of several fingers, which was sustained during a summit bid at $22,500 \mathrm{ft}$. Interestingly, the subject had no sensation of cold and it was not until he removed his gloves on returning to his tent that he noticed that his fingers were damaged. Treatment was by evacuation to Base Camp, systemic antibiotics, Vitamin C, and attempts to reduce his use of his hands. Fortunately, infection and further damage did not occur and the lesions dried out. On return to the UK the terminal phalanx of one digit was amputated.

The handling of medical problems on the mountain was greatly facilitated by the use of walky-talky type radios between the camps.

\section{Conclusion}

A medical officer is a considerable asset to a mountaineering expedition as he ensures that the important planning and preparation stages are properly carried out. His presence on the expedition relieves the leader of a number of responsibilities, for which he is not properly qualified, and in addition he adds considerably to the peace of mind of the other expedition members. 


\section{Acknowledgements}

The ambulatory monitoring electro-encephalogram research project was made possible by the generous support of the Wellcome Trust, the Jane Hodge Foundation and Oxford Medical Systems. The advice and assistance of Col P Abraham, Mr T Docherty, and the staff of the Clinical Measurement Departments of the Queen Elizabeth and the Cambridge Military Hospitals are most gratefully acknowledged in connection with this research.

\section{REFERENCES}

1. WARD, M P. Mountain medicine: a clinical study of cold and high altitude. London: Crosby Lockward Staples 1975.

2. Edholm, O G, Bacharach, A L Eds. Exploration medicine. Bristol, John Wright and Sons Ltd 1965.

3. Bonington, C. Everest - The hard way (Medical Annex). London: Arrow Books 1977.

4. AdAM, J M. A traveller's guide to health. London. Hodder and Stoughton 1966.

5. Clarke, C, Ward, M, Williams, E Eds. Mountain medicine and physiology. London: Alpine Club Symposium 1975.

6. Illingworth, $R$ N. Expedition medicine, a planning guide. Ambleside, Cumbria: Brathay Hall Trust 1978.

7. Hardie, $\mathbf{R} H$. Medical report. In Fleming, J, Faux, $\mathbf{R}$ Eds. Soldiers on Everest. London: HMSO 1977.

8. DiLly, N. Personal communication.

9. HoRniblow, P. Personal communication. 